\title{
A Summary of Researches on the Quality of Home-based Care Services in China
}

\author{
Yi-Luo Wang ${ }^{1}$, Ying Duan ${ }^{1} \&$ Ying Zhang ${ }^{1}$ \\ ${ }^{1}$ Shandong Technology and Business University, Yantai, Shandong, China \\ Correspondence: Yi-Luo Wang, Shandong Technology and Business University, Yantai, Shandong, China. E-mail: \\ 864547152@qq.com
}

Received: March 1, 2021 Accepted: March 17, 2021 Online Published: March 20, 2021

doi:10.5539/par.v10n1p41 URL: http://dx.doi.org/10.5539/par.v10n1p41

\begin{abstract}
With the increase of the aging of the population in china, the demand of the elderly continues to increase, which has brought great challenges to the elderly care service industry. As a new type of elderly care service, home-based care services directly affect the quality of the elderly's health and daily life in their later years. Therefore, improving the product and quality of elderly care services has become the goal and purpose of the development of home-based care service for aged. This article uses Cite Space software to perform visual analysis of keyword clustering on existing literature, and concludes that scholars focus on the integration of medical care, social elderly care service system, service quality, and influencing factors, but the impact of service quality models and indicator systems is low. Then through the integration and induction of scholars' research progress on home care services, existing problems in service quality, and service quality evaluation index systems, in order to continue to innovate on the basis of existing knowledge, improve the service quality index system, and focus on combing process indicators with outcome indicators effectively, thereby improving the quality of community home care services.
\end{abstract}

Keywords: community home-based care, service quality, evaluation index system

\section{Introduction}

With the intensification of the population aging process in China, the delay of the average life expectancy, the acceleration of cross-regional occupational mobility, and the miniaturization of traditional family structures, traditional family care functions have gradually weakened, while institutional elderly care is also unable to meet the needs of the elderly due to high operating costs and inadequate elderly care facilities. In 1987, the concept of community home-based care was first introduced in China, and this socialised elderly care service gained popularity and widespread attention, becoming the first choice for the elderly in China. Although community home care has been developed for more than 20 years and has made contributions to old-age security, the effect of implementation and the level of service are still unknown. A scientific and reasonable assessment of the quality of community home care services is the key to ensuring the quality of life of the elderly and promoting the improvement and development of community home care services. Therefore, the research on the evaluation index system of community home care service quality is of great significance both in theory and practice.

\section{Literature Review}

\subsection{The Concept of Community Home-Based Care Services}

\subsubsection{The Definition of Community Home-Based Care Services}

Home-based care service is to improve the lives of the elderly at home. The government and society rely on the community to provide them with services such as life care, housekeeping, medical care, etc, effectively combining social and family care (Yixiao Lian, 2016). Home care is oriented to the actual needs of the elderly, (Guoping Zhang, 2014), and there is variability in the service demand items of different elderly (Chenglin Xiao, Shuwen Yu, 2015). Previous scholars equated home care with "home care" + "social care", "home care" + "community care" or believed that community care at home was equivalent to home care, but the venue was different. This article believes that Professor Xiaoyi Zhang's (Xiaoyi Zhang, Bangcheng Liu, 2011) views of home-based care service are more reasonable and representative: Community home-based care services provide socialized services such as life care, rehabilitation care, and psychological comfort for the elderly at home. It takes the family as the core, relies on the community, and takes professional service organizations as the carrier, through the government to 
purchase services from social forces, and non-profit organizations implement cost-effective operation methods. For another, Community home-based care services are carried out in the form of volunteer visits, neighbourhood mutual assistance or day care, etc.

\subsubsection{The Features of Community Home-Based Care Services}

Xiaoyi Zhang (2012) believes that the products of urban home-based care services have the characteristics of nonstorability, intangibility, inseparability, and difference; However, it also has its own unique attributes, Chuanqing Liu (2019) elaborated as follows: the service content is diverse, the diversification of service providers, and the uncertainty of the service environment.

\subsubsection{The Content of Community Home-Based Care Services}

The content of community care for the elderly mainly focuses on four aspects: life care, psychological comfort, rehabilitation care, and culture and entertainment (Junhui Huang, 2015). Among them, life care is the foundation of community home-based care services, and the most demanded by the elderly for life care services are "assistance shopping, door-to-door delivery" and "door-to-door housework" (Zhangan Wang, 2015). On the other hand, rehabilitation care is the key, among which the demand rate of "rehabilitation treatment, medical staff visiting doctors, and visiting nursing" is the highest (Zhangan Wang, 2015). Spiritual comfort is indispensable, and what is often needed most is "cultural entertainment, chatting to relieve boredom, service hotline and legal assistance" (Huan Li,2016). Ling Yu and Yuming Wang (2009) link the elderly's needs for elderly care services with Maslow's hierarchy of needs theory. Mu Guangzong (2012) divides the needs of the elderly into three categories, in order of survival, development and value. The specific nursing service covers housing, mentality, and entertainment.

\subsubsection{The Provider of Community Home-Based Care Services}

Community home-based care services are public services, which are non-competitive and non-exclusive, and should be undertaken by the government. However, the government can choose to provide public services in a variety of ways. The government plays a leading role in the providers, and government-funded health service centers, non-profits Organizations, volunteer organizations, housekeeping companies, day care centers, homebased elderly service agencies, and elderly activity rooms can all participate in to promote the formation of a competitive market in the elderly service field and avoid inefficiency caused by monopoly.

\subsubsection{Research on Community Home-Based Care Service Model}

Wenjun Li believes that there are five main community home care service models, which they are time bank model, company partner model, network model, multi-integration model, and community home care service model based on labor exchange. In terms of supply mode, Qingchun Yan divides it into four modes: government-led, intermediary organization operation mode; government-sponsored, hierarchical linkage mode; government funding, institution-sponsored, chain operation mode; government purchase of service, company undertaking, and market operation mode.

\subsection{Research on the Quality of Community Home Care Services}

\subsubsection{The Concept of Service Quality}

Service quality is the core of service management. Foreign scholars have carried out extensive research since the 1970s. Levit first proposed the concept of service quality, that is, whether the service can meet the expected requirements. Parsauraman, Zeithaml and Berry (1985) believed that the comparison between the customer's "expected level" of the service and the "service effect" he actually felt produced the quality of service. Longsheng Cheng of domestic (2011) believes that service quality is the degree to which service characteristics and service support conditions meet requirements. Jun Deng (2014) believes that service quality is the sum of the characteristics and characteristics of whether a service can meet regulations and potential needs. Service quality has the characteristics of subjectivity, interaction, heterogeneity and integrity.

In summary, service quality refers to consumers' evaluation of the sum of the characteristics of the service's ability to meet their own explicit and implicit needs. It is a service quality evaluation based on the gap between the expected service level and the actual perceived service level. It is a measure of the enterprise The service level is a tool to meet customer expectations. It includes service results, service methods, and service processes.

\subsubsection{The Components of Service Quality}

The scope of service quality mainly includes service content, service process, service structure, service result and service impact. Chunxiao Wang (1999) through empirical research on hospitals believes that service quality can be decomposed into environmental quality and emotional quality. Chongde Yang (2005) quantitatively analyzed the service quality of different departments of the bank from three aspects: service quality capability, process and 
performance measurement. Tu Dongyan (2008) believes that service quality is composed of perceived quality, provided quality, image quality and process quality. Good perceived quality includes six standards: convenience and flexibility, professionalism and ability, service and remedy, reliability and trust, surplus and trustworthiness, attitude and behavior.

\subsubsection{Evaluation Methods of Service Quality}

Shuo Yang, Lili Cao (2017) think that existing classic theories of service quality evaluation include: one category includes service quality gap analysis model, SERVQUAL evaluation model, SERVPERF evaluation model, etc. The value orientation formed by the summary of competitive services includes functionality, Features such as economy, safety, timeliness, comfort, and civility; the other category includes $4 \mathrm{E}$ models, data envelopment analysis (DEA) models, etc. The value orientation formed by the summary of pure public services includes economy, efficiency, and benefit, Fairness and other characteristics.

\subsection{Research on the Evaluation Index System of my country's Community Home Care Service Quality}

2.3.1 Based on the SERVQUAL Model, a Service Quality Evaluation Index System is Constructed from Different Classifications of Service Content

SERVQUAL is the abbreviation of Service Quality. The evaluation method is based on customer perception, that is, the subjective perception of the customer is used to measure the quality of service. The customer's expectation of the service is measured first, and then the quality of the customer's perception of the service is measured. The difference between customer perception of service and expectations is compared to obtain the service quality of the enterprise, which is used as the basis for judging the level of service quality. The model mainly includes tangibility, reliability, responsiveness, guarantee behavior, and empathy.

From the perspective of service content, Chunling Bai (2016) used the SERVQUAL service quality model to construct a service quality evaluation index system from cleaning, catering, emergency assistance, and transportation assistance. Pingting Mou (2014) added two services from the perspective of medical assistance and recreation, but the system indicators are not comprehensive as a result of it does not taking the needs of the elderly for day care and nursing services into consideration.

From the perspective of the specific dimensions of the evaluation index system, Haihong Wen and Yihuan Wang (2019) believe that the selection of the "empathy" dimension for evaluating the quality of home care services in the community is not accurate and comprehensive. The "caring" of the service that whether it can give the elderly care and humanization is more reasonable as an evaluation dimension. Therefore, five dimensions of tangibility, reliability, responsiveness, guarantee and caring are selected in the evaluation of the quality of home community elderly care services. Shuaishuai Tian (2018) believes that the primary principle of home care services is to ensure the health and safety of the elderly, and reliability and guarantee are to ensure that home care service providers can fulfill their promises and their service quality is stable and trusted by the elderly. Therefore, on the basis of the SERVQUAL model, the "safety" dimension is added, and the "guarantee" dimension is deleted.

\subsubsection{Construct an Evaluation System for the Quality of Elderly Care Services from Other Models}

Xiaoyi Zhang, Qiang Mei (2012) constructs a performance evaluation index system for community home care services from the four aspects of economy, efficiency, effectiveness and fairness with the help of William. N. Dunn's "4E Theory". Liang Zhu (2019) explored the construction of a medical and elderly care integrated community home care center supply service quality evaluation index system scale in the basic of the evaluation model of "element-link-end". It mainly evaluates service quality from three different levels: the basic elements of service generation, the process links of service, and the end goal of service expectations. Song Xuecheng (2016) built a Shanghai home-based care service evaluation index system from three aspects: life care, medical care, and spiritual entertainment underlying the AHP-FCE model. The weight of related indicators was set through the AHP method, and a multi-level fuzzy was established. Comprehensive evaluation model. Yong Lan, Wang Zhenzhen, etc. (2018) ${ }^{[29]}$ based on the accessibility indicators of Panchaski and Thomas, and constructed five categories of availability, accessibility, affordability, acceptability, and adaptability. Through in-depth analysis, the two secondlevel indicators are finally decomposed into 23 third-level indicators, which comprehensively evaluate the accessibility of home care community services in Beijing, Nanjing and Xianyang.

\subsubsection{Evaluation System Based on Customer Satisfaction}

Peng Ji (2013) uses data envelopment analysis to evaluate the efficiency of the government's purchase of homebased care services and the satisfaction evaluation based on ACSI to evaluate the performance of home care services. Chuhui Liao (2014) and others conducted service satisfaction surveys from three first-level indicators, 8 second-level indicators, 20 third-level indicators, and 36 indicators, respectively, from the three first-level 
indicators of material conditions, life services, and spiritual comfort, and then to the city Evaluation of the quality of community home-based elderly service industry.

Service quality evaluation and satisfaction are easy to be confused, but there is actually a fundamental difference between the two. Satisfaction is a part of service quality evaluation, and service quality rating can be measured by customer satisfaction.

\section{Methodology}

\subsection{Visual Analysis}

Through the characterization and analysis of 374 core journals retrieved on CNKI with the keyword "community home care for the elderly", such as keyword co-occurrence and keyword clustering, it can be concluded: The number of research papers continues to increase, and scholars are mainly concerned about the current status of home-based care services, the integration of medical care, elderly care services, the social elderly care service system, service quality, and influencing factors. The research on service quality focuses on the analysis of its influencing factors, while the service quality model and indicator system pay less attention, and their centrality is less than 0.1 .

\begin{tabular}{llll}
\hline Frequent & Degree & Centrality & Keyword \\
\hline 14 & 5 & 0.13 & Influencing factors \\
6 & 6 & 0.11 & service quality \\
2 & 2 & 0.00 & Index system \\
1 & 1 & 0.00 & Service quality model \\
1 & 2 & 0.00 & Satisfaction \\
\hline
\end{tabular}

\subsection{Literature Research}

It is also called "historical research method" or "documentation research method". It uses various channels to collect relevant documents and materials comprehensively, to sort and analyze the documents, to grasp the relevant scientific research dynamics and frontier developments. Based on the achievements and research status of the predecessors, a method of conducting scientific research in a targeted manner according to the needs of one's own research. Generally speaking, the main sources of literature are related works and academic papers at home and abroad. By reading a large number of related literatures, this article systematically summarizes and summarizes on the basis of the existing research results, and provides theoretical basis and guidance methods for the construction of the community home care service quality evaluation index system.

\section{Findings}

Through combing related literature, it is found that the existing research mainly has the following shortcomings:

(1) Insufficient theoretical support for the evaluation of community home care service quality, and different conceptual understandings of home care services, resulting in different evaluation systems; (2) The difference in the dual structure of China's urban and rural areas has not been taken into account, and home care services have been widely used. Based on the analysis, there is a lack of targeted guidance for home care services in urban communities; (3) There is no unified evaluation standard for home care services in various regions, and there are large differences in the framework design of the indicator system, which makes it impossible to provide guidance for home care services in urban communities in China. The development status of elderly care services shall be uniformly evaluated; (4) The evaluation of home care services is a complex and exploratory new work involving a wide range of areas. There are no successful models and experiences in various regions. The establishment of the index system and the comprehensive evaluation method The application needs to be further improved.

\section{Discussion of the Results}

In summary, different scholars have given different reference models for the evaluation system of community home care service quality, but the index evaluation system mostly focuses on the evaluation of the results and process of the service qualification and service content of the nursing center, such as facilities, the evaluation of environment and service staff time are all aimed at the qualification of service organizations, and there are few result evaluations that directly reflect the effect. The evaluation of service effect is mainly based on indicators such as satisfaction. For example, the specific length of time the service personnel provide to an elderly person; and the 
effect of the service: Can the chronic disease of the elderly be improved? Has ADL's self-care ability improved? Is the pain reduced? Has depression decreased in Chengdu? Has the scope of communication for the elderly expanded? Or, after you or the elderly received these subsidies, what changes did you feel: feeling happier than before, etc. There are currently no targeted methods for evaluating service effects and it is difficult to measure, which adds difficulties to the establishment of a quality evaluation system. In addition, among so many rating indicator systems, some involve too many indicators, and some are too simple to be trustworthy.

Therefore, China should establish a specific scientific indicator system that takes into account the situation of ageing, and innovate on the basis of foreign tools for evaluating the quality of elderly services.

\section{Limitations of the Present Study and Suggestions for Future Research}

In the theoretical analysis of the construction of the community home care service evaluation index system, how to dig deeper into relevant theories such as government performance evaluation theory, community care theory and satisfaction theory, and combine the process, service effect and service benefit of community home care service, Exploring the theoretical basis suitable for the evaluation of community home-based care services will be an important topic for further research.

\section{Conclusion}

The ultimate research purpose of community home care service quality evaluation is to improve the measures of community home care services and improve the level of community home care services. Therefore, summarize and evaluate the experience and lessons of the central government and various local governments in the development of community home care services in recent years, and use the indicator system to identify the gap between the actual results of the work and the predetermined goals, and analyze various preferential policies for home care services. The success or failure of the implementation process, to find out the key factors that affect the further development of the quality of home care services, so as to provide relevant government departments with targeted and actionable countermeasures and suggestions is the research direction of home care service evaluation.

\section{References}

Bai, C. L. (2016). Research on SERVQUAL-based community home care service quality evaluation index system. World of Labor and Social Security, (14), 3.

Cheng, L. S., Niu, J. L., \& Shi, J. Z. (2012). Customer satisfaction model for highway long-distance passenger transportation and its application. Mathematical Statistics and Management, 31(01), 15-25.

Deng, J., Ma, X. J., \& Zhang, J. F. (2014). A review of the research on the service quality evaluation of archives. Archives Science Research, (03), 60-66.

Huang, J. H., Li, F., \& Zhao, G. (2015). Analysis of the Willingness of Rural Social Pension Service Demand and Its Influencing Factors: Jiangsu Data. Journal of China Agricultural University (Social Sciences Edition), 32(2), 118-126.

Ji, P., \& Li, F. (2013). Performance evaluation of government purchasing home care services: practical exploration and index system construction. Theory and Reform, (03), 104-107.

Li, H., Zhang, X. M., \& Wu, X. L. (2016). Survey on the needs of the elderly in the community for home care services. Chinese Journal of Gerontology, 36(5), 1171-1173.

Li, W. J. (2018). Research on performance evaluation of community home-based care services. China University of Political Science and Law Press.

Lian, Y. X., Jia, X. C., \& Lu, F. (2016). Influencing factors of the demand for home care services in the rural areas of Henan Province. Journal of Zhengzhou University (Medical Edition), 51(5), 606-610.

Liao, C. H., Gan, W., \& Chen, J. (2014). Evaluation of the quality of home care services in the first-tier cities in China. Journal of Zhongnan University of Economics and Law, (02), 46-50.

Liu, C. Q. (2019). Research on Service Quality Management Issues of Community Home Care Service Supply Chain. Harbin University of Commerce.

Mou, P. T. (2014). Research on the Evaluation Index System of Community Home Care Service Quality. Dalian: Dalian University of Technology.

Mu, G. Z. (2012). Difficulties and countermeasures for the development of institutional elderly care in my country. Journal of Central China Normal University: Humanities and Social Sciences Edition, 51(2), 31-38.

Parasuraman, A., Berry Leonard, L., \& Zeithaml Valarie, A. (1983). Service firms need marketing skills. 
https://doi.org/10.1016/0007-6813(83)90043-5

Song, X. C. (2016). Evaluation of Shanghai Home Care Service Quality Based on AHP-FCE Model. Journal of Baoding University, 29(4), 21-28.

Tian, S. S. (2018). Research on the quality of home care services based on the SERVQUAL model. Northwest University.

Tu, D. Y. (2008). The role of knowledge management in improving enterprise performance. Shanghai Quality, (02), 15-17.

Wang, Z. G., Yang, L., \& Teng, X. P. (2015). The needs of home care services for the elderly in the community of Nanning City. Chinese Journal of Gerontology, 35(22), 6535-6537.

Wen, H. H., \& Wang, Y. H. (2019). Analysis of the quality of home-based community care services and its influencing factors: based on survey data from three cities in Shaanxi Province. Journal of Hebei University (Philosophy and Social Sciences Edition), 44(2), 139- 148.

Xiao, C. L., \& Yu, S. W. (2015). Research on the home care model of farmers in new rural areas. Journal of Qiqihar University (Philosophy and Social Science Edition), (1), 67.

Yang, C. D. (2005). Customer Satisfaction: A Key Improvement Factor for Bank Quality Management - A Measurement and Analysis of 40,000 Customer Satisfaction Questionnaires. Rural Finance Research, (06), $37-40$.

Yang, S., Cao, L. L., Hou, F., \& Zeng, Y. (2017). The practice and standardization of home care service quality evaluation from an international perspective. Social Policy Research, (05), 10-17.

Yong, L., Wang, Z. Z., \& Zhang, D. M. (2018). The accessibility of community services for the elderly at home conceptual model, index system and comprehensive evaluation. Population and Economy, (04), 1-11.

Yu, L., \& Wang, Y. M. (2009). Research on the elderly care services in urban communities in Shanghai. World of Labor and Social Security, 8, 063.

Zhang, G. P. (2014). Analysis of the demand for home care services for the rural elderly and its influencing factors: Based on the social survey of Jiangsu Province. Population and Development, 20(2), 95.

Zhang, X. Y. (2012). Research on the Quality of Home Care Services in Urban Communities. Jiangsu University.

Zhang, X. Y., \& Liu, B. C. (2011). Research on the model of community home care service quality: Taking Shanghai as an example. China Population Science, (03), 83-92+112.

Zhang, X. Y., \& Yan, P. Y. (2007). Exploration of the evaluation index system for the urban home care for the aged. Shanghai: Baijia Publishing House.

Zhu, H., Wang, C. X., Cen, C. D., \& Xie, L. S. (1999). An Empirical Study on the Attributes of Service Quality. Business Research, (06), 3-5.

$\mathrm{Zhu}, \mathrm{L}$ (2019). The construction of the evaluation index system for the quality of the supply service of the community home-based elderly care center with the integration of medical care and care. North China University of Technology.

\section{Copyrights}

Copyright for this article is retained by the author(s), with first publication rights granted to the journal.

This is an open-access article distributed under the terms and conditions of the Creative Commons Attribution license (http://creativecommons.org/licenses/by/4.0/). 